THE INTERNATIONAL MIGRATION OF KNOWLEDGE WORKERS: WHEN IS BRAIN DRAIN BENEFICIAL?

Peter J. Kuhn

Carol McAusland

WORKING PAPER 12761 


\title{
THE INTERNATIONAL MIGRATION OF KNOWLEDGE WORKERS: WHEN IS BRAIN DRAIN BENEFICIAL?
}

\author{
Peter J. Kuhn \\ Carol McAusland \\ Working Paper 12761 \\ http://www.nber.org/papers/w12761
NATIONAL BUREAU OF ECONOMIC RESEARCH
1050 Massachusetts Avenue
Cambridge, MA 02138

December 2006

Kuhn received support from Industry Canada contract 5017079 on the International Mobility of Highly Skilled Workers during the early stages of this project. The authors acknowledge helpful comments from seminar participants at the University of California, Santa Barbara. The views expressed herein are those of the author(s) and do not necessarily reflect the views of the National Bureau of Economic Research.

(C) 2006 by Peter J. Kuhn and Carol McAusland. All rights reserved. Short sections of text, not to exceed two paragraphs, may be quoted without explicit permission provided that full credit, including $\odot$ notice, is given to the source. 
The International Migration of Knowledge Workers: When is Brain Drain Beneficial?

Peter J. Kuhn and Carol McAusland

NBER Working Paper No. 12761

December 2006

JEL No. F22,J61

\begin{abstract}
$\underline{\text { ABSTRACT }}$
We consider the welfare effects of the emigration of workers who produce a public good (knowledge). We distinguish between the knowledge diversion and knowledge creation effects of such emigration, and show that the remaining residents of a country can gain from emigration, even when tastes for knowledge goods exhibit a kind of 'home bias'. In contrast to existing models of beneficial brain drain (BBD), our results do not require agglomeration economies, education-related externalities, remittances, return migration, or an emigration 'lottery'. Instead, they are driven purely by the public nature of knowledge goods, combined with differences in market size that induce greater knowledge creation by emigrants abroad than at home. BBD is even more likely in the presence of weak sending-country intellectual property rights (IPRs), or when source country IPR policy is endogenized.
\end{abstract}

Peter J. Kuhn

Department of Economics

UC, Santa Barbara

2127 North Hall

Santa Barbara, CA 93106

and NBER

pjkuhn@econ.ucsb.edu

Carol McAusland

Agricultural and Resource Economics

UNiversity of Maryland

College Park, MD 20742-5535

cmcausland@arec.umd.edu 


\section{Introduction.}

Will a "brain drain" from a small, or low-wage economy hurt or help the remaining residents of that economy? While the earliest economics literature on this question (e.g. Berry and Soligo 1969, Bhagwati and Hamada 1974) suggested that harm was likely, recent contributions have identified a number of factors that could give rise to beneficial brain drain (BBD). These include increased incentives to acquire education in the sending country (Mountford 1997), remittances (e.g. Ozden and Schiff 2006), and added discipline on the sending country's tax authorities (Bucovetsky 2003).

In this paper we study another possible source of beneficial brain drain: the direct benefit to sending-country consumers that occurs when its brains move to an environment where they produce higher-quality knowledge goods. More specifically, we model brains as "knowledge workers", whose efforts improve the quality of a good that is reproducible at zero marginal cost (Rosen 1981). ${ }^{1}$ Improvements in the quality of such goods benefit source-country consumers whether their brains live at home or abroad. Thus, for example, scientists sent to a U.S. laboratory, actors sent to Hollywood, and programmers sent to Silicon Valley may produce products of greater value to their origin-country consumers than the products they would have produced at home. Of course, both the amount of home bias in tastes, and the strength of intellectual property rights (IPRs) in the sending and receiving countries will affect the magnitude of these gains in consumer welfare. We study these effects as well.

What factors might induce a sending country's brains to produce higher-quality knowledge goods when employed abroad? While we can think of several --including agglomeration economies and a stronger IPR environment-- in order to illustrate the distinct nature of the causal mechanisms studied here, our most basic model assumes identical production costs and full IPRs in both the sending and receiving countries. The welfare gains from brain drain come instead from market size and home-bias effects: If the foreign market is sufficiently larger than the sending country's, and if knowledge produced abroad is not too irrelevant to consumers in the sending country, the extra incentives to produce knowledge created by this larger market mean the (remaining residents of) the home country are better off allowing their knowledge workers to emigrate. Later in the paper we introduce differences in intellectual property rights, showing that (a) weak domestic IPRs accentuate the gains from knowledge worker emigration, and (b) if source country IPRs are chosen endogenously, BBD becomes even more likely than in the base case. Both of these results stem from the source country's ability to "free ride" on its own brains after they leave.

\footnotetext{
${ }^{1}$ The term "knowledge worker" was coined by Peter Drucker (1959); since then it has become a truism that the production of new knowledge is an essential and growing component of a developed economy . It is therefore surprising that a defining characteristic of knowledge -its publicness - has not, to our knowledge, yet been incorporated into formal models of international skilled worker migration.
} 


\section{Existing Literature}

As noted, the earliest economics literature on the "brain drain" (e.g. Berry and Soligo 1969), and indeed on international factor mobility in general (e.g. Jones, Coelho and Easton 1986), focused on induced changes in domestic factor prices and producer surplus in an undistorted "sending" economy. Although exceptions exist (for example the two-good, two-factor small open economy model in which factor rewards are independent of factor endowments, and the case of large countries whose terms of trade are advantageously affected by a factor outflow), in most of these models the reduction in opportunities to trade with differently-endowed agents makes remaining residents worse off after an outflow of skilled labor. ${ }^{2}$

Since then, economists have identified a number of factors that accentuate the harm associated with a "brain drain". One such factor is a fiscal externality: in the presence of publicly-subsidized education and progressive taxation, the exodus of highly educated workers imposes a net fiscal loss on the sending country's remaining residents (Bhagwati and Hamada 1974). Also, in an endogenous growth context, some authors have argued that an outflow of educated workers can inflict a very high level of harm in the long run by reducing a country's growth rate (Miyagiwa 1991, Wong and Yip 1999). ${ }^{3}$

Over the same time period, however, the literature has identified a number of factors working in the opposite direction, generating what is sometimes referred to as "beneficial brain drain" (BBD). Probably the oldest such argument is the notion that emigration provides a social "safety valve" for unemployed skilled workers in less developed countries (see for example the discussion in Bhagwati and Rodriguez 1975). Two additional factors --by no means confined to skilled workers-- are emigrants' cash remittances to the home country (e.g. Ozden and Schiff 2006), and the return migration of "brains" who have acquired new skills abroad (possibly at foreign taxpayers' expense). ${ }^{4}$ Less obviously, Stark, Helmenstein and Prskawetz $(1997,1998)$ have argued that the possibility of emigrating and earning a higher wage can raise incentives to acquire education in less-developed sending countries. If this effect is strong enough relative to the actual outflow of educated workers, the "sending" country's stock of skilled workers can of course rise. Extending this "emigration lottery" reasoning to an endogenous growth framework, Mountford (1997) has shown that the temporary possibility of skilled-worker emigration can "jump-start" an economy out of a poverty trap.

\footnotetext{
${ }^{2}$ Despite its age, the argument still figures prominently in contemporary policy discussions about international labor mobility (e.g. Borjas 1995). Of course, nothing in the argument is specific to skilled labor: it pertains to any non-infinitesimal factor outflow that does not mirror the nation's factor endowment mix exactly.

${ }^{3}$ Introducing a skilled worker outflow into more traditional growth models (where growth occurs purely via either human or physical capital accumulation) has less dramatic negative long run effects (see, e.g. Rodriguez 1975).

${ }^{4}$ According to DeVoretz (2005), it is precisely this prospect of return migration that led China to relax its exit requirements in the early 1990s.
} 
Most recently, Bucovetsky (2003) and Haupt and Janeba (2004) have considered the discipline that skilled emigration could impose on tax authorities in skilled-worker "sending" countries: human capital, once acquired, is sunk and therefore vulnerable to over-taxation by governments with limited commitment power. By constraining governments' abilities to tax human capital, the possibility of brain drain can induce those governments to act in their country's own long run interests, thus raising the long term level of human capital investment and per-capita income.

In addition to the literatures on brain drain and international factor mobility, the current paper also relates to recent work on intellectual property rights, including Grossman and Lai (2004). These authors examine countries with different market sizes, and show that equalizing IPRs across countries may hurt a human-capital poor country; further such equalization is not necessary to provide optimal aggregate incentives for innovation. Helpman (1993) examines IPRs in a model of endogenous, ongoing innovation, and shows that weakening IPRs in a single country can benefit both that country and its trade partner; the welfare gain arises when weakening IPRs in high-wage North shifts production to low-wage South. Neither of these models, however, examine the effects of international labor migration.

\section{The Model}

We focus on a single knowledge worker, or "artist". The artist produces a prototype knowledge good; the prototype can be replicated costlessly. The prototype might be, for example, a musical recording, an insight into the laws of physics, or a malaria vaccine.

Market willingness to pay for reproductions depends on both the quality, $\rho$, and relevance, $t$, of the knowledge good, each to be discussed below. We assume individual inverse demand for a reproduction is given by $\operatorname{top}(q)$ where $p(q)$ is a decreasing function of quantity consumed per capita, $q$. We can interpret $p(q)$ as base inverse demand, i.e. as marginal willingness to pay for a unit of a knowledge good with $100 \%$ relevance and quality 1 . Define $\varepsilon \equiv-\frac{1}{d p(q) / d q} \frac{p(q)}{q}$ as the elasticity of base demand. An interior solution to the profit maximization problem requires $\varepsilon$ be decreasing in $q$, which we assume throughout the remainder of the paper.

The variable $\rho$ captures the intrinsic quality of a good, for example, if the good is a treatment for influenza, $\rho$ may index the speed with which the treatment reduces flu symptoms. We draw a distinction between quality and applicability, or relevance: ever since Armington (1969), several economists (e.g. Trefler 1995) have argued that consumers may prefer locally produced goods to otherwise-identical imports. ${ }^{5}$ In the current paper we operationalize home bias via an iceberg "translation" cost $1-\tau$; we can

\footnotetext{
${ }^{5}$ Empirical studies tend to find strong evidence of home bias in consumption. For example, Whalley and Xin (2006) find home bias can account for over $90 \%$ of the measured border effect in US-Canada trade.
} 
think of $\tau$ as the fraction of a knowledge good's value that survives translation to a foreign market. Recalling terminology introduced above, let $t^{i j}$ measure the relevance to consumers in market $i$ of a knowledge good developed in market $j$; then with iceberg translation costs $t^{i j}=1$ for $i=j$ and $t^{i j}=\tau \in[0,1]$ for $i \neq j$; accordingly, we can think of $\tau \rho$ as the net premium for imported, or translated, goods. We treat $\tau$ as a parameter outside the artist's and government's control, however we acknowledge that $\tau$ will vary with the type of knowledge good considered: for instrumental music $\tau$ may be near unity; the $\tau$ associated with comedy is often remarked to be close to zero. ${ }^{6}$

If emigration is legal, the artist faces a two-stage problem. First she must decide where to live and work, and second she must decide what quality prototype to produce and how to price it to each market. As usual, we begin with the second stage.

\section{1 Stage Two: Profit Maximization}

We simplify the world into two countries: Source $(S)$ and Recipient $(R)$. Let $N^{i}$ be the number of consumers in country $i \in\{S, R\}$. Define $\pi^{i}=\max _{q} p^{i}(q) q$ as the artist's maximized per capita base profits from market $i$, and $q^{i}=\operatorname{argmax}_{q} p^{i}(q) q$ as her optimal per capita deliveries to this market. ${ }^{7}$ Note that our inverse demand functions are indexed by country (i); this allows per-capita income differences to enter our model with higher income assumed to shift the inverse demand curve upwards. In this section we assume that both Source and Recipient provide full legal protection of intellectual property rights (IPRs). Thus the artist is an uncontested monopolist in both markets, and will choose $q^{i}$ such that $\varepsilon=1$ in each market. Using these definitions, we can rewrite the artist's total profits from market $i$ when residing in country $j$ as $N^{i} t^{i j} \rho \pi^{i}$. Further, the artist can treat $\pi^{S}$ and $\pi^{R}$ as parameters when solving her investment and location problems.

Improving the quality of the prototype comes at a price. The knowledge worker may hire complementary inputs (a scientist outfitting a better lab), acquire additional human capital (voice lessons for an opera singer, a post doc for a biologist), or simply put in more effort (work longer hours). We will refer to any such actions as investments. Let $c(\rho)$ measure the total cost of producing a prototype of quality $\rho$. We assume the marginal cost of improving prototype quality is positive and increasing, i.e. $c^{\prime}(\rho)$ and $c^{\prime \prime}(\rho)$ are both positive; define

$$
\psi \equiv c^{\prime \prime} \rho / c^{\prime}
$$

as the elasticity of the marginal investment cost. In general, $\psi$ is a function of $\rho$, although on occasion we will adopt the following assumption:

\footnotetext{
${ }^{6}$ Importantly, the home bias in our paper refers to the artist's current location, not his/her country of birth; thus we assume that, for example, Indian consumers treat goods produced by Indian expatriates in the United States similarly to goods produced by other Americans. In part, this is based on a very prevalent notion in the business literature that close contact (in our case living in the same country and culture) with consumers is essential to producing innovations that customers like (see for example Ulwick 2002).

${ }^{7}$ Because $\varepsilon$ is decreasing in $q$, base profits $p^{i}(q) q$ are locally concave at $q^{i}$ and $q^{i}$ is unique.
} 
A1: $c$ is iso-elastic in $\rho$, i.e. $\psi$ is a constant.

The artist chooses the quality of her prototype based on the following calculation: $\max _{\rho} \rho\left[t^{S j} N^{S} \pi^{S}+t^{R j} N^{R} \pi^{R}\right]-c(\rho)$. Define $M^{j} \equiv t^{S j} N^{S} \pi^{S}+t^{R j} N^{R} \pi^{R}$, which measures the size of the artist's effective global base market when residing in country $j$. Thus we can rewrite the artist's investment problem when residing in country $j$ as

$$
\max _{\rho} \rho M^{j}-c(\rho)
$$

A convex cost function (i.e $d^{2} c / d \rho^{2}>0$ ) ensures the second order conditions for an interior maximum, while the first order condition

$$
M^{j}=c^{\prime}(\rho)
$$

implicitly defines $\rho\left(M^{j}\right)$ as the price premium corresponding to the artist's optimal investment when residing in country $j$. Because higher values of $\rho$ reflect higher quality knowledge goods, we can interpret an increase in $\rho$ as knowledge creation; differentiating the first order condition we see $d \rho(M) / d M=1 / c^{\prime \prime}>0$. Hence, if an action by the artist or a government increases the size of the artist's effective market, that action will in turn have a knowledge creation effect.

\subsection{Stage One: Emigration}

We assume zero relocation costs. Since the artist earns more when $M$ is larger, she will move to wherever her residency confers the largest global base market. If the artist remains in Source, her effective market is $M^{S} \equiv N^{S} \pi^{S}+\tau N^{R} \pi^{R}$. If instead she emigrates to Recipient her market is $M^{R} \equiv \tau N^{S} \pi^{S}+N^{R} \pi^{R}$. For $\tau<1$, whether $M^{S}<M^{R}$ depends only on relative populations and base profits. Assuming the artist stays home when indifferent, we obtain the following lemma and proposition.

Lemma 1. If translation costs are non-zero (i.e. $\tau<1$ ), the artist emigrates if and only if $N^{S} \pi^{S}<N^{R} \pi^{R}$.

If both countries have the same individual inverse demand curves (for example because their per capita income levels and tastes are the same), Lemma 1 implies that the artist optimally locates herself in the country with the largest population for any non-zero level of translation costs. Of course, the artist might optimally choose a country with smaller population if its consumers were sufficiently richer than the other country.

Proposition 1: Voluntary emigration induces knowledge creation.

\section{Proof:}

By Lemma 1 the artist emigrates voluntarily if and only if $N^{R} \pi^{R}>N^{S} \pi^{S}$, which is equivalent to the condition $M^{R}>M^{S}$ for $\tau<1$. Since $d \rho / d M>0$ then $\rho\left(M^{R}\right)>\rho\left(M^{S}\right)$ and so emigration leads to higher quality knowledge goods. 
If $N^{R} \pi^{R}>N^{S} \pi^{S}$ then Recipient offers a larger effective market than Source. Since the artist can take better advantage of that market by relocating to Recipient, she emigrates. Once immersed in the Recipient market, the artist responds to the increased returns on her investment, producing a higher quality prototype.

\section{Beneficial Brain Drain}

We now turn our attention to conditions under which brain drain is beneficial to the parties involved. In order to minimize the number of cases that must be described, we restrict our attention in the remainder of the paper to cases in which the artist will emigrate if allowed, i.e. in which $N^{R} \pi^{R}>N^{S} \pi^{S}$.

Clearly consumers in Recipient and the artist all benefit from voluntary emigration if, as assumed so far, both Source and Recipient offer full legal IPR protection. A simple revealed preference argument confirms that the artist benefits. To see that consumers in Recipient gain, we look at their consumer surplus, denoted CS. Following usual methods and factoring out terms, in our model

$$
C S^{i j}=N^{i} t^{i j} \rho \Phi^{i}
$$

gives consumer surplus in country $i$ when the artist resides in country $j$, where

$$
\Phi^{i}=\int_{0}^{q^{i}} p(q) d q-p\left(q^{i}\right) q^{i}
$$

is "base" consumer surplus per capita, i.e. consumer surplus associated with qualityunadjusted goods, when $q^{i}$ units are sold per capita in country $i$. Notably, $\Phi^{i}$ is independent of $\rho$.

Proposition 2: Recipient consumers gain from voluntary migration.

Proof:

Without migration, $C S^{R S}=N^{R} \tau \rho\left(M^{S}\right) \Phi^{R}$. With migration, $C S^{R R}=$ $N^{R} \rho\left(M^{R}\right) \Phi^{R}$. Thus migration benefits Recipient consumers if and only if $\rho\left(M^{R}\right)>\tau \rho\left(M^{S}\right)$, which is assured by $\tau \leq 1$ and Proposition 1 .

Recipient consumers gain from the Artist's immigration on two counts. Firstly, they benefit from the knowledge creation stemming from their large native market. Secondly, migration induces knowledge diversion. To the extent that the flavor and applicability of a knowledge worker's prototype is influenced by her environment, some of the value of an artist's output is "lost in translation" to overseas consumers. When the artist resides in Source, Recipient's consumers suffer $1-\tau$ in translation losses. Alternately, we can think of $1-\tau$ as the local component of knowledge goods; this local component accrues only to the artist's fellow residents. Emigration transfers this local component of the artist's knowledge good from Source's consumers to Recipient's. This knowledge diversion is 
to Recipient's unambiguous benefit. However it comes at Source's expense, and must be weighed against the rate of knowledge creation.

Proposition 3: Source's consumers are made better off from voluntary migration if and only if the rate of knowledge creation is greater than the rate of knowledge diversion, i.e.

$$
\frac{\rho\left(M^{R}\right)-\rho\left(M^{S}\right)}{\rho\left(M^{R}\right)}>1-\tau \text {. }
$$

\section{Proof:}

Following the proof of Proposition 2, emigration raises Source's consumer surplus if and only if $\rho\left(M^{R}\right) \tau>\rho\left(M^{S}\right)$. Multiplying each side by -1 , adding $\rho\left(M^{R}\right)$ and then converting to ratios gives the equivalent condition (1).

Proposition 3 formalizes the condition that the knowledge creation effect of emigration must dominate the knowledge diversion effect in order for brain drain to benefit Source's consumers. However, because (1) is written in terms of endogenous values, it does not tell us under which parameter conditions BBD occurs.

Proposition 4: Define $\bar{\psi} \equiv \frac{N^{R} \pi^{R}-N^{S} \pi^{S}}{N^{R} \pi^{R}+N^{S} \pi^{S}}$.

(a) If the gap in relative market size exceeds the elasticity of marginal investment costs, i.e.

$$
\psi\left(\rho\left(N^{R} \pi^{R}+N^{S} \pi^{S}\right)\right)<\bar{\psi} \equiv \frac{N^{R} \pi^{R}-N^{S} \pi^{S}}{N^{R} \pi^{R}+N^{S} \pi^{S}},
$$

then there exists a non-empty interval $(\bar{\tau}, 1)$ of translation rates under which voluntary emigration benefits Source's consumers, where $\bar{\tau} \in(0,1)$.

(b) If Al holds and (2) is satisfied then there exists a value $\bar{\tau}$ that divides the interval [0,1] as follows: if (2) holds and $\tau\left\{\begin{array}{c}<\bar{\tau} \\ =\bar{\tau} \\ \in(\bar{\tau}, 1) \\ =1\end{array}\right\}$ then brain drain is $\left\{\begin{array}{c}\text { harmful } \\ \text { neutral } \\ \text { beneficial } \\ \text { neutral }\end{array}\right\}$ to Source's consumers.

(c) If A1 holds and (2) is violated then Brain Drain is harmful to Source's consumers for any $\tau \in[0,1)$.

Proof: See Appendix

Corollary 1: Under A1, when condition (2) holds, there exists a non-empty interval $(\bar{\tau}, 1)$ of translation rates under which voluntary emigration is Pareto welfare improving. 
Part (a) of Proposition 4 provides a sufficient condition for $\mathrm{BBD}$; if in addition investment costs are iso-elastic, i.e. condition Al holds, then parts (b) and (c) provide necessary and sufficient conditions for BBD. Figure 1 plots the rates of knowledge creation, $\left[\rho\left(M^{R}\right)-\rho\left(M^{S}\right)\right] / \rho\left(M^{R}\right)$ and diversion, 1- $\tau$, when condition (2) holds. Clearly, the possibility of $\mathrm{BBD}$ depends on the curvature of the cost function and the size of the translation cost. Because the right hand term in condition (2) can be no larger than unity, a necessary condition for BBD is that marginal costs be inelastic in $\rho$, i.e. $\psi<1$. This is not inconsistent with investment costs being convex in quality: if $c$ is iso-elastic, for example, convexity requires only that $\psi$ be positive. Rather, the constraint that $\psi<1$ simply requires that investment costs not rise too quickly with quality.

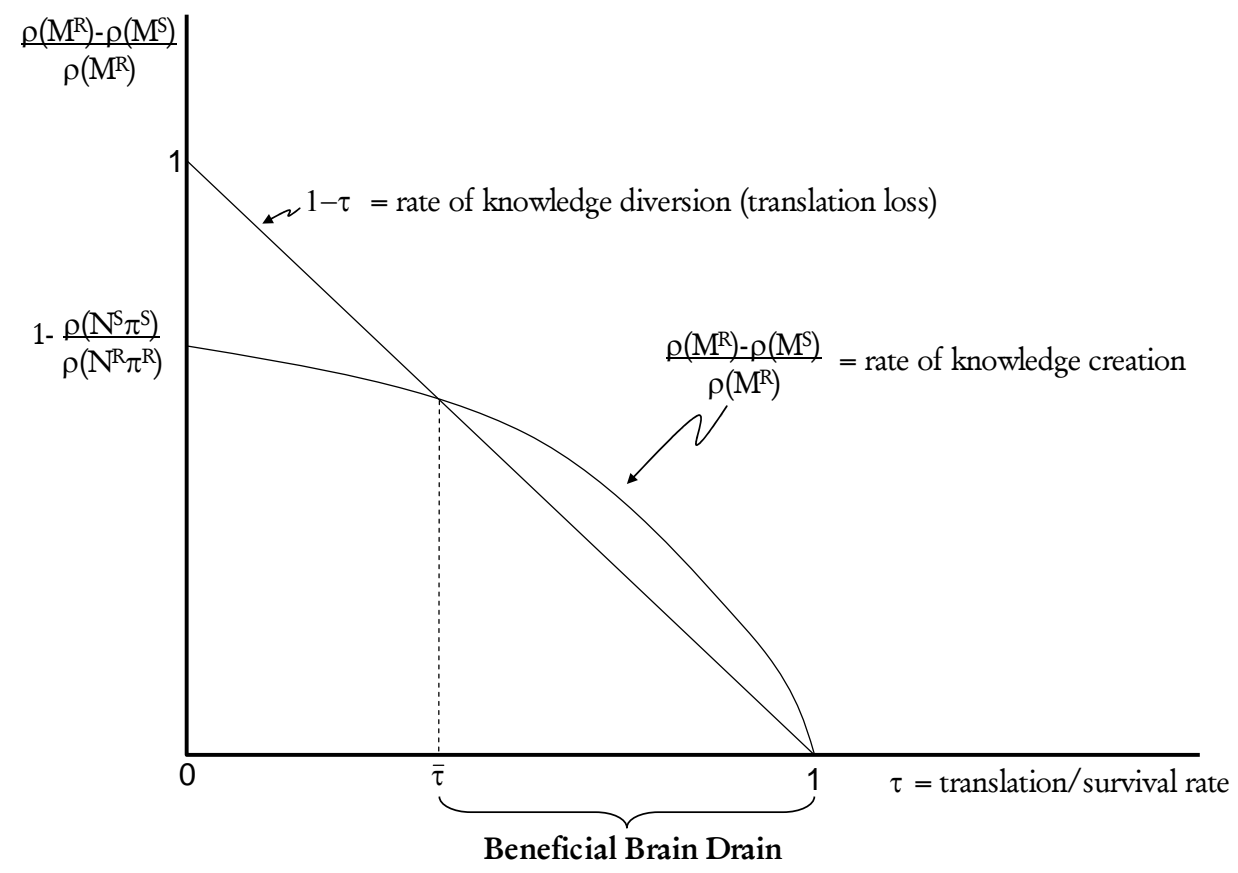

Figure 1: knowledge creation versus knowledge diversion

Another critical parameter is $\tau$. If translation losses are complete, i.e. $\tau=0$, then knowledge creation is irrelevant to Source's consumers since they won't be able to understand, or make use of, any of it. Conversely, if $\tau=1$ then any additional knowledge created will be perfectly useful to Source's consumers; however, because $M^{S}$ and $M^{R}$ would be identical, emigration would leave $\rho$ unchanged. But, if $\tau$ has an intermediate value, then voluntary emigration prompts investment and some of that quality improvement survives translation. If $\tau$ is not too small, the net value of the artist's product will rise for Source's consumers, rendering brain drain beneficial. Figure 1 nicely illustrates how both differences in effective market size and home bias (i.e. "translation costs") are required for BBD: if there is no home bias, knowledge workers can serve the entire world equally well from wherever they live; thus there is no efficiency gain from sending them into a large consumer market such as the U.S.

The final determinant of whether (2) holds, and hence whether BBD is possible, is Source's relative size. 
Proposition 5. Under A1, the range of cost-elasticities and translation costs under which Brain Drain is beneficial to Source's consumers are each larger the smaller is Source's aggregate base profits $N^{S} \pi^{S}$ relative to Recipients, $N^{R} \pi^{R}$. Specifically, $\frac{d \bar{\psi}}{d \alpha}<0<\frac{d \bar{\tau}}{d \alpha}$ where $\alpha \equiv \frac{N^{S} \pi^{S}}{N^{R} \pi^{R}}$.

Proof: See Appendix.

Proposition 5 simply states that brain drain is more likely to benefit the Source country when aggregate base profits in Source are small. Some of the factors determining aggregate base profits, e.g. the size of the native population as well as their income level --the latter being a determinant of base demand $p(q)$ )-- are outside the control of policymakers, at least in the short run. However, since the goods in question are knowledge goods, goods which can be reproduced at essentially zero cost, then $\pi^{S}$ may depend critically on de jure and de facto rules governing intellectual property rights (IPRs), which are the subject of the next section.

\section{Brain Drain and Intellectual Property Rights}

This section poses two questions. First, we ask how the previous section's conclusions, derived for the case of full intellectual property rights in both countries, change when IPRs are fixed at some other exogenous level that can differ across countries. This generates a set of comparative statics for the effects of IPRs on the gains (or losses) from knowledge worker emigration. Second, we endogenize IPR policy by characterizing a (potential) sending country's best combination of emigration and IPR policies. The goal of this exercise is to see whether (or when) BBD is still optimal when the source country has access to a broader array of policy tools. ${ }^{8}$

The strength of a country's IPRs can be measured along two dimensions: the breadth of its fair use rules, and the zeal with which it enforces its rules. We consider only the case in which fair use rules are very tight, and so the consumer must purchase one copy of the artist's prototype for each application (e.g. one copy of an operating system for the user's desktop, another copy for his laptop), but where enforcement is imperfect. In particular, a competitive fringe sells pirated reproductions of the artist's prototype at marginal cost. Assume constant returns to scale in producing pirated goods, and denote their marginal cost by $d$. Assuming pirates have access to the same reproduction techniques as the artist, the materials portion of $d$ is zero. Thus $d$ reflects only the expected costs of getting caught distributing copyrighted materials. In

\footnotetext{
${ }^{8}$ For simplicity, in conducting this exercise we continue to characterize Source's emigration policy as a simple choice between "closing its exits", i.e. prohibiting emigration, or not (rather than, for example, an emigration tax). Given our earlier restriction $N^{S} \pi^{S}<N^{R} \pi^{R}$, brain drain is inevitable unless Source's exitdoors are closed; thus open-exit policy is synonymous with "Brain Drain" in our discussion.
} 
particular, we assume $d$ equals the probability of detection multiplied by the (nonmonetary) penalty for piracy. For parsimony, we assume the penalty is proportional to the price premium, $t \rho$, for the translated good. This means the marginal cost in country $i$ of pirated copies of a prototype produced in country $j$ can be written

$$
d^{i j}=\beta^{i} t^{i j} \rho
$$

where $\beta^{i}$ is increasing in the strength of i's IPR enforcement. This $\beta^{i}$ proxies the strength of de facto IPRs, and equals the base price of pirated goods.

When facing a competitive fringe with marginal cost $d$, the artist becomes a contested monopolist. We assume that all demand goes to the artist if legal and pirated goods are offered at the same price. Decomposing $d^{i j}$ as indicated in (3), the contested monopolist's optimization problem in market $i$ becomes

$$
\max _{q} N^{i} t^{i j} \rho p(q) q \text {, s.t. } p(q) \leq \beta^{i}
$$

As is usual with constrained monopoly, we can write the artist's maximized per capita base profits as a piecewise function of $\beta$ :

$$
\pi(\beta) \equiv\left\{\begin{array}{c}
p^{-1}\left(\beta^{*}\right) \beta^{*} \\
p^{-1}\left(\beta^{i}\right) \beta^{i}
\end{array}\right\} \text { for } \beta^{i}\left\{\begin{array}{l}
\geq \\
<
\end{array}\right\} \beta^{*}
$$

where $\beta^{*}$ is the base price the artist would set absent any competition and $p^{-1}(\cdot)$ is the inverse of function $p(\cdot)$.

Lemma $2 \pi(\beta)$ is increasing in $\beta$ for $\beta<\beta^{*}$.

Proof:

For $\beta<\beta^{*}, d \pi(\beta) / d \beta=p^{-1}(\beta)[1-\varepsilon]$. Since $\varepsilon$ is decreasing in $q$ and $\varepsilon$ is unity at the uncontested monopoly output $p^{-1}\left(\beta^{*}\right)$, then, for any $\beta<\beta^{*}, \varepsilon<1$ and thus $d \pi(\beta) / d \beta>0$.

For $\beta<\beta^{*}$, it follows that the artist's total profits from market $i$ when residing in country $j$ can now be written as: $N^{i} t^{i j} \rho \pi^{i}(\beta)$, where $d \pi(\beta) / d \beta>0$; the only change from the case of full IPRs is that $\pi^{i}$ is now a function of $\beta$ (but, importantly, not of $\rho$ ). In the full-IPR case, we were able to treat these total profits as exogenous conditional on $N^{i}$, $t^{i j}$ and $\rho$. Now, profits are exogenous conditional on $N^{i}$, $t^{i j}$ and $\rho$ and $\beta^{i}$.

Recall that at the outset of Section 3 we restricted our attention to cases in which $N^{S} \pi^{S}<N^{R} \pi^{R}$. As we are now treating $\pi$ as endogenous via $\beta$, we refine this restriction as follows:

$$
\text { A2. } N^{S} \pi^{S}\left(\beta^{*}\right)<N^{R} \pi^{R}
$$

Given Lemma 1, Assumption A2 ensures that Source is too small to be attractive to the artist even if Source fully protects intellectual property. 
Assumption A2 is not innocuous. It hinders our analysis from applying to large Source countries whose ample population and income levels would allow Source a second means of preventing emigration: offering sufficiently strong local IPRs. As before, we rule out such possibilities for the sake of brevity. We note, though, that it is possible to show that a large country may prefer to forego strong IPRs---suffering Brain Drain as a result---if translation costs are small relative to the deadweight loss from market power.

We next look at the properties of consumer surplus when pirates are at play. Define $C S^{S j}(\beta)$ as Source's consumer surplus when Source IPR's are $\beta$ and the artist resides in country $j$ :

$$
C S^{S j}(\beta)=N^{S} t^{S j} \rho \Phi^{S}\left(\beta^{S}\right)
$$

where

$$
\Phi^{S}\left(\beta^{S}\right)=\int_{0}^{p^{-1}\left(\beta^{S}\right)} p(q) d q-\beta^{S} p^{-1}\left(\beta^{S}\right)
$$

Comparing this to the equivalent expression in the full-IPR case, the only change is that source-country per-capita base surplus, $\Phi^{S}$, now depends on the IPR parameter, $\beta$ (but again, not on $\rho$ ). It is easy to show that $d \Phi^{S} / d(\beta)=-p^{-1}(\beta)<0$; i.e. holding product quality fixed, stricter IPRs (and therefore higher prices) make consumers worse off.

We are now in a position to consider the effects of brain drain on source consumer surplus at any exogenous level of IPR in both the sending (S) and receiving (R) countries, and to ask how Source's optimal emigration policies depend on IPR in the two countries. Without emigration, Source country consumer surplus is $N^{S} \rho\left(M^{S}\right) \Phi^{S}\left(\beta^{S}\right)$; with emigration, it is $N^{S} \rho\left(M^{R}\right) \tau \Phi^{S}\left(\beta^{S}\right)$. Thus, source consumers gain from brain drain if and only if $N^{S} \tau>\rho\left(M^{S}\right) / \rho\left(M^{R}\right)$, or if condition (1) holds. Importantly, while strict source country IPRs (higher $\beta^{S}$ ) directly reduce source consumer surplus, their direct effect on source consumer surplus is the same whether emigration occurs or not. Thus the condition for Source to gain from brain drain is the same as in the presence of full IPRs (equation 1); the only difference is the need to account carefully for the effects of IPRs on product quality via the effective market sizes, $M^{S}$ and $M^{R}$. To do this, note that when IPRs are less than full, effective market sizes are:

$$
M^{S} \equiv N^{S} \pi^{S}\left(\beta^{S}\right)+\tau N^{R} \pi^{R}\left(\beta^{R}\right)
$$

and

$$
M^{R} \equiv \tau N^{S} \pi^{S}\left(\beta^{S}\right)+N^{R} \pi^{R}\left(\beta^{R}\right)
$$

which are identical to the previous conditions with the exception that per-capita base profits now depend on IPR policies in both the sending and receiving countries, $\beta^{S}$ and $\beta^{R}$. It follows that the effects of an exogenous increase in Source IPRs (a rise in $\beta^{S}$ ) on 
optimal emigration policy are identical in direction to the effects of an increase in sourcecountry population, $N^{S}$, or for that matter to an exogenous increase in source-country base profits $\left(\pi^{S}\right)$ (caused for example by an increase in source country income). The proofs of Propositions 4 and 5 both go through exactly as before, with a rise in $\beta^{S}$ (or a fall in $\beta^{R}$ ) equivalent to a rise in $\alpha$. Thus, in the sense formalized in Proposition 5, an exogenous rise in IPR protection in Source (Recipient) makes BBD less (more) likely.

The intuition behind these results is fairly straightforward. As we have shown, for any fixed source IPR policy (and therefore a fixed base price for the knowledge good), the only effect of brain drain on Source consumers is via its effects on the quality and appropriateness of the knowledge good. The larger the differential in IPR protection between the recipient and source country, the larger the increment to quality will be when Source's brains move abroad, making beneficial brain drain more likely. In sum, if Source has low IPR protection for reasons that lie outside our model (for example, its legal system and enforcement technology may simply not be capable of a high level of enforcement), Source's interests are more likely to involve sending its knowledge workers abroad and consuming better (if culturally less appropriate) entertainment, science and technology as a result. If Recipient (again for reasons outside our model, such as a politically powerful knowledge industry) has very strong IPR protections, again it may behoove Source to "let its knowledge workers go".

Our final exercise in this paper involves endogenizing IPR policy. The goal in doing so is not so much to provide a realistic model of IPR policy (this choice has been studied in detail by Grossman and Lai, 2004, among others), but to ask how our main results regarding the optimality of beneficial brain drain in the limiting case where we allow countries to optimally adapt their IPR policies to their emigration policy regime. We do so in full recognition that not all important factors affecting optimal IPR policy are included in our model.

We begin by differentiating our expression for source-country consumer surplus (4) with respect to $\beta$ (while appropriately allowing for the endogeneity of product quality, $\rho)$, yielding:

$$
\frac{d C S^{S j}(\beta)}{d \beta}=p^{-1}(\beta) N^{S} t^{S j} \rho\left[\frac{N^{S} t^{S j}[1-\varepsilon(\beta)] \Phi(\beta)}{M^{j} \psi^{j}}-1\right],
$$

or, if $\beta>0$, equivalently:

$$
\frac{d C S^{S j}(\beta)}{d \beta}=\frac{C S^{S j}}{\beta} \underbrace{\left[\frac{\lambda^{S j}[1-\varepsilon(\beta)]}{\psi^{j}}-\frac{\pi(\beta)}{\Phi(\beta)}\right]}_{\equiv \Delta(\beta, j)}
$$

where $\lambda^{i j} \equiv t^{i j} N^{i} \pi^{i} / M^{j}$ is country $i$ 's contribution to the artist's effective global market when the artist lives in country $j$. 
Lemma 3. Under A1, $C S^{S j}$ is strictly (locally) concave in $\beta$ at any extremum.

Proof: See Appendix.

Referring to (6), whether strict IPRs raise or lower Source's consumer surplus depends on the sign of $\Delta(\beta, j) \equiv\left[\frac{\lambda^{S j}[1-\varepsilon(\beta)]}{\psi^{j}}-\frac{\pi(\beta)}{\Phi(\beta)}\right]$. The first term in $\Delta$ reflects the investment effects of raising $\beta$ : stronger Source IPRs translate to higher base profits for the artist, prompting greater investment; the second term in $\Delta$ measures the loss in base consumer surplus arising from consumers having to pay higher prices per (base) unit. We can think of these as the investment and consumption effects of strong IPRs. Define $\beta^{O}$ and $\beta^{C}$ as Source's optimal choice of $\beta$ when its doors are open and closed, respectively.

Proposition 6: Under $A 1$ and $A 2$,

(a) If Source offers any IPR protection at all, it offers weaker policy when its exits are open than closed. Specifically, $\beta^{O}<\beta^{C}$ if and only if

$$
\frac{N^{S}[1-\varepsilon(0)] \Phi(0)}{\psi\left[\tau N^{R} \pi^{R}\right]}>1
$$

if (7) fails then $\beta^{O}=\beta^{C}=0$.

(b) Source never offers full IPR protection: $\beta^{O} \leq \beta^{C}<\beta^{*}$.

Proof: See Appendix.

Intuitively, Source's optimal IPR policy balances the investment and consumption effects described above. Since the investment effects are dissipated as $\beta$ approaches $\beta^{*}$, Source will always offer less than full IPRs when the artist's residency is given. Moreover, when the Artist lives abroad rather than in Source, the investment incentives associated with high $\pi^{\mathrm{S}}$ are diluted by translation losses. Thus the investment effect of high $\beta$ is weaker when Source's exits are open, rendering strong IPRs less attractive to Source.

We are now in a position to revisit our earlier claims concerning when/whether Brain Drain might benefit the Source country. In particular, Proposition 4 provided a sufficient condition for Source to gain from BD under the condition that Source IPR policy was full. However, as Proposition 6 highlights, Source has an incentive to set weaker IPR policy when suffering from Brain Drain. The following extends Proposition 4 to allow for endogenous IPRs.. 
Proposition 7. Suppose Source's IPRs are set optimally given exit policy, i.e. $\beta=\beta^{O}$ when Source's exits are open and $\beta=\beta^{C}$ when Source's exits are closed. Define $\bar{\tau}(\beta)$ as the non-unity value of $\tau$ at which $\tau=\frac{\rho\left(N^{S} \pi^{S}(\beta)+\tau N^{R} \pi^{R}\right)}{\rho\left(\tau N^{S} \pi^{S}(\beta)+N^{R} \pi^{R}\right)}$. Under $A 1$,

$$
\frac{N^{R} \pi^{R}-N^{S} \pi^{S}\left(\beta^{C}\right)}{N^{R} \pi^{R}+N^{S} \pi^{S}\left(\beta^{C}\right)}>\psi
$$

is a sufficient condition for Source to prefer an open-exit policy in lieu of closed-exits for some non-empty range $\left(\tau^{1}, 1\right)$ of translation costs;

(b) if condition (7) holds then $\tau^{1}<\bar{\tau}\left(\beta^{C}\right)$.

Proof: See Appendix.

Part (a) of Proposition 7 offers a sufficient condition for brain drain to benefit Source even when Source adjusts its IPRs to complement its emigration policy. The underlying logic is the same as for Proposition 4: emigration transfers the local component of knowledge goods away from Source's consumers---what we have coined knowledge diversion; in exchange, the large market that attracts mobile knowledge workers in the first place prompts them to produce higher quality goods, inducing knowledge creation. This basic principle is unchanged by endogenous IPRs. However, as Part (b) of Proposition 7 indicates, the range of translation costs at which brain drain is beneficial is larger when IPRs are endogenous rather than fixed (and full). This is because endogenous IPRs open up a second channel through which Source can benefit from the artist's emigration to a large overseas market. Simply, Source can manipulate domestic IPRs to raise consumers' share of the benefits from knowledge creation: by lowering $\beta$, i.e. by weakening domestic IPRs, Source can raise $\Phi$, allowing Source's consumers to reap a greater share of the benefits from any increase in $\rho .{ }^{9}$ A case in point might be Canada's policies on drug pricing and medical researcher emigration: Canada's policies of keeping the prices of drugs (including those invented in the U.S.) well below U.S. levels actually accentuates the gains to Canadian consumers from allowing medical researchers to emigrate to the U.S.

Finally, we revisit our earlier suggestion that BBD is more likely when Source has a small native population. This claim may seem innocuous given Proposition 5, but if $\pi^{S}$ is endogenous then a proper proof should account for any influence that $N^{S}$ has over Source's IPR policy.

Proposition 8. Under A1, larger countries have incentives to set stricter IPRs: $d \beta^{k} / d N^{S} \geq 0$ for $k \in\{O, C\}$.

Proof: See Appendix.

\footnotetext{
${ }^{9}$ Of course, raising $\Phi$ by lowering $\beta$ will in turn reduce $\pi$, and so the knowledge creation effect will be smaller---but still positive ---when Source IPRs are endogenous.
} 
Corollary 2. A Source country is more likely to benefit from brain drain the smaller is its native population $N^{S}$.

Proposition 8 indicates that bigger economies have incentives to set stricter IPRs. The intuition is straightforward: the large base profits associated with strict Source IPRs are more meaningful (to the Artist) when Source's native market constitutes a larger share of the artist's global market. Conversely, when Source is small its IPRs have a weaker investment effect, rendering strict IPRs less attractive to Source. Thus we can confirm that Source's effective market size $N^{S} \pi^{S}$ is increasing in $N^{S}$, both directly and indirectly via $\pi^{S}(\beta)$, and so by Proposition 5 we can conclude that countries with small populations are more likely to gain from brain drain.

\section{Discussion}

In the late twentieth century, the worldwide pattern of information goods production and IPR protection had three distinct features. First, knowledge goods production was highly concentrated in a single country with a large domestic market (in most cases the United States). ${ }^{10}$ Second, a significant share of these goods was produced by immigrants to that country. ${ }^{11}$ Third, intellectual property rights protection was strongest in the producing country and weaker in other countries, including the source countries from which migrating knowledge workers were drawn. While the exodus of talented "brains" to larger, richer economies is sometimes bemoaned in sending countries, this paper shows that, under quite general conditions, all the above features could be in the interests of both the migrating knowledge workers and the remaining residents of the nations that send them. Remaining residents benefit because "their" brains produce "better" knowledge (such as more effective medicines, more entertaining movies, or more effective software) abroad than if they had remained at home.

Some noteworthy features of our model include the following. First, beneficial brain drain "BBD" is possible even when (a) the sending country places no welfare weight on the utility of its expatriates, (b) knowledge/cultural goods are less culturally relevant to the source market when produced abroad, that is, when demands exhibit home bias, or "losses in translation", and (c) both sending and receiving countries fully protect knowledge workers' intellectual property rights in a national treatment framework.

\footnotetext{
${ }^{10}$ Using purchasing power parity measures of R\&D activity, Dougherty et al (2003) find that expenditures in the US exceeded the combined expenditures of the next four leading research nations, Germany, Japan, France and UK. In 2000, 34.3\% of Triadic Patent Families (defined by the OECD as "patents taken out at the European Patent Office (EPO), the Japanese Patent Office (JPO) and the US Patent \& Trademark Office ( USPTO) that share one or more priorities") were taken out by American residents. The comparable proportions for residents of Japan and the EU are 26.9 and 31.4 (Source: OECD, Patent Database, September 2004.) The international predominance of the United States as a source of commercial popular culture is well known.

${ }^{11}$ In addition to entertainers, this of course includes scientists and engineers working in U.S. firms and universities. Nearly one in five scientists and engineers in the United States is an immigrant; 51 percent of US doctorates in engineering are currently awarded to foreigners (Zakaria 2005).
} 
Second, while we acknowledge that agglomeration economies may be important in explaining the location of many industries (e.g. Rivera-Batiz and Romer 1991) and a potential source of beneficial emigration, such external economies are not present in our model. Instead, the international specialization (via the migration of producers to a single country) derives simply from differences in domestic market size and home bias in tastes. Of course, in an expanded model there could be other important factors that induce expatriate "brains" to produce more and better knowledge when located in a country like the United States than at home; not least among these are the ability to cooperate with other factors of production (including critical masses of highly skilled workers) that the U.S. has already produced (or imported). Thus a natural extension of the current model would be to a dynamic context in which critical masses, or "clusters" of knowledge workers are created endogenously; importantly however these dynamics are not essential to the basic argument here.

Third, source countries' gains from brain drain depend on intellectual property rights in both the sending and receiving countries-- rising with weaker sending country and with stronger receiving country IPR protection. The likelihood that brain drain benefits the source country also increases when we expand its menu of policy tools to include an optimal choice of IPRs. Thus it may be in the interests of a small, or poor country to simultaneously specialize out of knowledge goods production (even actively sending its talented knowledge workers abroad) and keep the price of knowledge goods low by setting weak IPRs.

Finally, the level of home bias in consumers' tastes has interesting effects in our model. If we think of our parameter $\tau$ (the fraction of a knowledge good's value that survives export to another country) as rising over time due to declines in international transportation and communications costs, then our model predicts that source countries' benefits from brain drain will be minimal when international communication is poor, and will then rise as the ability of knowledge workers in one country to serve consumers in another rises. It is only in the limiting case of zero 'home bias' $(\tau=1)$--where knowledge workers can serve the world's consumers equally well from any location-where better international communication eliminates the gains to consumers in a small or poor country from sending their brains abroad.

Our results may have interesting implications for policies affecting "brain drain" in small, or poor countries that have not, to our knowledge, been noted before. For example, skilled-emigrant-sending countries may want to refine their policies (or at least their discussion of the issue) by distinguishing emigrants according to the "publicness" of the goods they produce. Thus, for example, the emigration of a physician who spends all of her time treating patients (a private good) may be more likely to hurt the remaining residents of her country than the emigration of a physician primarily engaged in research on new treatments and medicines (the sort of knowledge good modelled in this paper).

We close by asking why the existing literature on the "brain drain" has apparently not noticed the simple consumption effect of emigration on remaining residents that sits at the core of the current paper. We conjecture that this is because the literature has not, 
to date, considered the production of "knowledge goods" that can be reproduced at zero marginal cost. Instead, all existing models of international factor mobility of which we are aware treat skilled workers simply as an input to the production of private goods. To the extent that knowledge produced by skilled workers has "public" qualities, this has been modelled as a production externality where the presence of more skilled workers makes other workers in the country where they live more efficient at producing private goods (e.g. Mountford 1997). ${ }^{12}$ The consumption benefits to sending countries of knowledge produced by expatriates have thus tended to be ignored; we hope the present model encourages more exploration of this important aspect of international skilled worker flows.

\footnotetext{
${ }^{12}$ In principle, one could of course construct a model in which private goods imported from the U.S. become cheaper to Indian consumers as a result of Indian "brains" migrating to the U.S., but to our knowledge no such model has been developed.
} 


\section{References}

Armington, Paul S. "A Theory of Demand for Products Distinguished by Place of Production." International Monetary Fund Staff Papers March 1969, 16(1): 159-78.

Berry, R. and R. Soligo, "Some welfare aspects of international migration" Journal of Political Economy 77 (1969).

Bhagwati, J. and K. Hamada, "The brain drain, international integration of markets for professionals and unemployment: A theoretical analysis". Journal of Development Economics 1(1) (1974)

Bhagwati, J. and C. Rodriguez. "Welfare-Theoretical Analyses of the Brain Drain" Journal of Development Economics 2 (1975) 195-221.

Borjas, George J. "The Economic Benefits From Immigration," Journal of Economic Perspectives, 1995, 9(2), 3-22.

Bucovetsky, S. "Efficient Migration and Income Tax Competition" Journal of Public Economic Theory. April 2003; 5(2): 249-78

Commander, Simon, Mari Kangasniemi, and Alan L. Winters. "The Brain Drain: Curse or Boon? A Survey of the Literature" in Robert E. Baldwin and L. Alan Winters, eds. Challenges to globalization: Analyzing the economics. NBER Economic Research Conference Report series. Chicago and London: University of Chicago Press, 2004; 235-72.

DeVoretz, D. "International Mobility of Highly Skilled Workers: Quo Vadis?" Mimeo, Simon Fraser University, 2005.

Dougherty, Sean M., Robert Inklaar, Robert H. McGuckin, and Bart Van Ark. "Internationalization and the Changing Structure of Business R\&D: Recent Trends and Measurement Implications" mimeo 2003, The Conference Board and Growth and Development Center of the University of Groningen.

Drucker, Peter. Landmarks of Tomorrow. New York: Harper, 1959.

Grossman, Gene M. and Edwin L.-C. Lai. "International Protection of Intellectual Property" American Economic Review (December 2004): 1635-1653.

Haupt, A. and E. Janeba. "Education, Redistribution, and the Threat of Brain Drain". NBER working paper no 10618, June 2004.

Helpman, Elhanen. "Innovation, Imitation and Intellectual Property Rights," Econometrica, 61 (1993), p. 1247-1280

Jones, R.W., I. Coelho and S. Easton, 1986, The theory of international factor flows: The basic model, Journal of International Economics 20, 313-327.

Manasse, Paolo, and Alessandro Turrini. "Trade, Wages and 'Superstars"” Journal of International Economics 54 (2001), pp. 97-117. 
Miyagiwa, Kaz. "Scale Economies in Education and the Brain Drain Problem" International Economic Review. August 1991; 32(3): 743-59

Mountford, A. (1997) "Can a Brain Drain be Good for Growth in the Source Country?" Journal of Development Economics 53, 287-303.

OECD. The Knowledge-Based Economy. Paris: OECD, 1996.

Oettl, A. and A. Agrawal. "You Can't Take it With You-- Or Can You? Exploring International Labour Mobility and Knowledge Flows" Mimeo, University of Toronto, 2005.

Ozden, Caglar and Maurice Schiff, eds. International Migration, Remittances, and the Brain Drain Washington, D.C.: World Bank; Houndmills, U.K. and New York: Palgrave Macmillan, 2006.

Rivera-Batiz, Luis A., and Paul M. Romer. "Economic Integration and Endogenous Growth" Quarterly Journal of Economics 106 (2) (May 1991): 531-555.

Rodriguez, C. (1975) "On the Welfare Aspects of International Migration" Journal of Political Economy 1975.

Rosen, Sherwin. "The Economics of Superstars" American Economic Review Vol. 71, No. 5. (Dec.1981), pp. 845-858

Stark, O., C. Helmenstein and A. Prskawetz (1997) "A Brain Drain with Brain Gain” Economics Letters 55, 227-234.

Stark, O., C. Helmenstein and A. Prskawetz (1998) "Human Capital Depletion, Human Capital Formation, and Migration: A Blessing or a Curse?" Economics Letters 60, 363-367.

Vidal, J.-P. (1998) "The Effect of Emigration on Human Capital Formation" Journal of Population Economics 11, 589-600.

Trefler, Daniel. 1995. "The Case of the Missing Trade and other Mysteries," American Economic Review 85(5): 1029-1046.

Ulwick, Anthony W. "Turn Customer Input into Innovation" Harvard Business Review 80(1) (January 2002): 91-97

Whalley, John and Xian Xin. 2006. "Home and Regional Biases and Border Effects in Armington Type Models," NBER Working Paper No. 12439.

Wong, Kar-yiu and Chong Kee Yip. "Education, economic growth, and brain drain" Journal of Economic Dynamics and Control 23 (1999) 699-726.

Zakaria, Fareed. "The Wealth of Yet More Nations". Review of T. Friedman, The World is Flat: A Brief History of the Twenty-First Century, New York Times Book Review, May 1, 2005, pp. 10-11. 


\section{Appendix}

\section{Proof of Proposition 4:}

Part (a). Rearranging Proposition 3 indicates voluntary brain drain is beneficial to Source's consumers if and only if

$$
\frac{\rho\left(M^{S}\right)}{\rho\left(M^{R}\right)}<\tau
$$

Define $\Gamma(\tau) \equiv \frac{\rho\left(M^{S}\right)}{\rho\left(M^{R}\right)} . \Gamma(\tau=0)=\frac{\rho\left(N^{S} \pi^{S}\right)}{\rho\left(N^{R} \pi^{R}\right)}$ is positive and less than unity, while $\Gamma(\mathrm{t}=1)=1$; therefore, if $\mathrm{d} \Gamma / \mathrm{d} \tau>1$ when $\tau=1$, then the continuity of $\Gamma$ in $\tau$ ensures there exists a nonempty interval $(\bar{\tau}, 1)$ over which $\Gamma(\tau)<\tau$, where $\bar{\tau} \in(0,1)$. Differentiating $\Gamma$ with respect to $\tau$ gives

$$
\frac{d \Gamma}{d \tau}=\Gamma\left[\frac{N^{R} \pi^{R}}{M^{S} \psi\left(\rho\left(M^{S}\right)\right)}-\frac{N^{S} \pi^{S}}{M^{R} \psi\left(\rho\left(M^{R}\right)\right)}\right] .
$$

Evaluating at $\tau=1$ gives

$$
\left.\frac{d \Gamma}{d \tau}\right|_{\tau=1}=\frac{1}{\psi\left(\rho\left(N^{R} \pi^{R}+N^{S} \pi^{S}\right)\right)}\left[\frac{N^{R} \pi^{R}-N^{S} \pi^{S}}{N^{R} \pi^{R}+N^{S} \pi^{S}}\right]
$$

which is greater than unity if and only if (2) holds.

Part (b). Given A1, we can write $\Gamma \equiv\left(\frac{M^{S}}{M^{R}}\right)^{1 / \psi}$. Define $\alpha$ such that $N^{S} \pi^{S}=\alpha N^{R} \pi^{R}$ where $\alpha<1$. This allows us to write $\Gamma=\left(\frac{\alpha+\tau}{\alpha \tau+1}\right)^{1 / \psi}$ while $\bar{\psi}=\frac{1-\alpha}{1+\alpha}$. Twice differentiating $\Gamma$ with respect to $\tau$ when $\psi$ is constant gives

$$
\frac{d^{2} \Gamma}{d \tau^{2}}=\frac{\Gamma}{\psi} \frac{\left(1-\alpha^{2}\right)}{(\tau \alpha+1)^{2}(\tau+\alpha)^{2}}\left[\frac{1-\alpha^{2}}{\psi}-\alpha^{2}-2 \alpha \tau-1\right]
$$

which is positive for all $\tau \in[0,1]$ if and only if $\psi<\bar{\psi}$. Hence whenever (2) holds, $\Gamma$ is globally convex in $\tau$ and thus $\bar{\tau} \in(0,1)$ divides the unit interval into regions where brain drain is and is not beneficial to Source's consumers.

Part (c). Differentiating $\Gamma$ with respect to $\tau$ gives

$$
\frac{d \Gamma}{d \tau}=\frac{\Gamma}{\psi}\left[\frac{1-\alpha^{2}}{(\tau \alpha+1)(\alpha+\tau)}\right] .
$$

If $\psi>\bar{\psi}$ then $d \Gamma / d \tau$ is less than unity whenever $\tau$ is such that $\Gamma=\tau$. Hence the $1-\Gamma$ curve cannot cross the 1- $\tau$ line in Figure 1 from above. Moreover, since $\Gamma=1$ when $\tau=1$ and 
$\left.\frac{d \Gamma}{d \tau}\right|_{\tau=1}<1$ then $\Gamma \leq \tau$ is ruled out whenever $\psi>\bar{\psi}$ and $\tau<1$. Finally, suppose $\psi=\bar{\psi}$; then $\Gamma$ is strictly convex in $\tau$ for $\tau<1$. Moreover, since $\Gamma>0$ for $\alpha>0$ when $\tau=0$, while $\Gamma$ and $d \Gamma / d \tau$ are both unity when $\tau=1$, then $\Gamma \leq \tau$ is ruled out whenever $\psi=\bar{\psi}$.

\section{Proof of Proposition 5:}

Rewriting condition (2) in Proposition 4 in terms of $\alpha$ gives $\bar{\psi}=\frac{1-\alpha}{1+\alpha}$, which is decreasing in $\alpha$. Hence the range of cost elasticities $(0, \bar{\psi})$ for which brain drain is beneficial for some translation costs contracts with $\alpha$. Moreover, when (2) is satisfied, $\frac{d \Gamma}{d \alpha}=\frac{\Gamma}{\psi}\left[\frac{1}{\alpha+\tau}-\frac{\tau}{\alpha \tau+1}\right]>0$ for $\tau<1$, which implies $d \bar{\tau} / d \alpha>0$; thus the smaller is $\alpha$, the larger the interval $(\bar{\tau}, 1)$.

\section{Proof of Lemma 3:}

Differentiating the right hand term in (5) with respect to $\beta$ and evaluating at any extremum gives

$$
\frac{d^{2} C S^{S j}(\beta)}{d \beta^{2}}=p^{-1}(\beta) N^{S} t^{S j} \rho \frac{N^{S} t^{S j}}{\psi^{j}}\left[-\frac{\Phi(\beta)}{M^{j}} \frac{d \varepsilon(\beta)}{d \beta}+\frac{1-\varepsilon}{M^{j}} \frac{d \Phi(\beta)}{d \beta}-\frac{[1-\varepsilon] \Phi}{\left[M^{j}\right]^{2}} \frac{d M^{j}}{d \beta}\right]
$$

Because $\varepsilon$ is decreasing in $q, \varepsilon$ is non-decreasing in $\beta$; since higher prices translate to lower consumer surplus, $\mathrm{d} \Phi / \mathrm{d} \beta<0$; since profits are increasing in $\beta, \mathrm{d} \mathrm{M}^{\mathrm{j}} / \mathrm{d} \beta>0$. Hence $\frac{d^{2} C S^{S j}(\beta)}{d \beta^{2}}<0$ at any extremum of $\mathrm{CS}^{\mathrm{Sj}}$.

\section{Proof of Proposition 6:}

We prove Part (b) first. Since the artist's marginal costs of reproduction are zero, if her monopoly power is uncontested then she sets prices such that $\varepsilon=1$. From equation (5), $\frac{d C S^{S j}(\beta)}{d \beta}<0$ whenever $\varepsilon=1$, thus Source never offers full intellectual property protection if the artist's residency is fixed. Finally, when A2 holds, Source's exit-policy fully determines the artist's residency; thus Source can treat the artist's residency as invariant to $\beta$ within a given exit-policy regime. 
Part (a). When (7) fails then, from equation (5), $\frac{d C S^{S j}(\beta)}{d \beta} \leq 0$ for $\mathrm{j} \in\{\mathrm{S}, \mathrm{R}\}$ and so Source sets $\beta^{k}=0$ for $k \in\{O, C\}$. If instead (7) holds then $\beta^{\mathrm{C}}>0$; by part (b), $\beta^{\mathrm{C}}<\beta^{*}$. Hence $\beta^{\mathrm{C}}$ takes an interior value; from equation (6), $\beta^{\mathrm{C}}$ solves $\Delta\left(\beta^{C}, S\right)=\frac{\lambda^{S S}[1-\varepsilon]}{\psi^{S}}-\frac{\pi\left(\beta^{C}\right)}{\Phi\left(\beta^{C}\right)}=0$. By Lemma 3, A1 implies $C S$ is locally concave in $\beta$. Using (6), evaluating $d C S^{S R}(\beta) / d \beta$ at $\beta^{C}$ and factoring out like terms gives

$$
\left.\frac{d C S^{S R}(\beta)}{d \beta}\right|_{\beta=\beta^{C}}=\frac{C S^{S k}\left[1-\varepsilon\left(\beta^{C}\right)\right]}{\beta^{C} \psi}\left[\lambda^{S R}-\lambda^{S S}\right] .
$$

Since $\lambda^{S R}<\lambda^{S S}$ under A2, then A1 implies $\left.\frac{d C S\left(\beta ; M^{R}\right)}{d \beta}\right|_{\beta=\beta^{C}}<0$, hence $\beta^{\mathrm{O}}<\beta^{\mathrm{C}}$.

\section{Proof of Proposition 7:}

Part (a): Define $C S^{k}(\beta)$ as Source's consumer surplus when Source's IPR policy is $\beta$ and exit-door policy is $k \in\{$ open, closed\}. By Proposition 4 , equation (8) is a sufficient condition for $C S^{\text {open }}\left(\beta^{C}\right)>C S^{\text {closed }}\left(\beta^{C}\right)$ whenever $\tau \in\left(\bar{\tau}\left(\beta^{C}\right), 1\right)$. Revealed preference ensures $C S^{\text {open }}\left(\beta^{O}\right) \geq C S^{\text {open }}\left(\beta^{C}\right)$.

Part (b): When condition (7) holds then, by Proposition $6, \beta^{C}>\beta^{O}$. Since Source's consumer surplus is strictly locally concave in $\beta$ by Lemma 3 , then $C S^{O}\left(\beta^{O}\right)>C S^{O}\left(\beta^{C}\right)=C S^{C}\left(\beta^{C}\right)$ when $\tau=\bar{\tau}\left(\beta^{C}\right)$. Since $C S^{O}\left(\beta^{O}\right)>C S^{C}\left(\beta^{C}\right)$ at $\tau=\bar{\tau}\left(\beta^{C}\right)$, then $\tau^{l}<\bar{\tau}\left(\beta^{C}\right)$.

\section{Proof of Proposition 8:}

By the envelope theorem and the local concavity of $\mathrm{CS}^{\mathrm{Sj}}$ in $\beta$, if $\beta^{\mathrm{k}}$ is unconstrained then $\operatorname{sign}\left[\frac{d \beta^{k}}{d N^{S}}\right]=\operatorname{sign}\left[\frac{d}{d N^{S}} \frac{d C S^{S j}}{d \beta}\right]$. Differentiating (6) with respect to $N$ under A1 gives

$$
\frac{\partial}{\partial N^{S}} \frac{d C S^{S j}}{d \beta}=\frac{C S^{S j}}{\beta} \frac{1-\varepsilon(\beta)}{\psi^{j}} \frac{\partial \lambda^{S j}}{\partial N^{S}}+\frac{\Delta}{\beta} \frac{\partial C S^{S j}}{\partial N^{S}}
$$

where $\frac{\partial \lambda^{S j}}{\partial N^{S}}=\frac{\lambda^{S j}\left[1-\lambda^{S j}\right]}{N^{S}} \geq 0$. Because $\Delta=0$ at $\beta^{\mathrm{k}}$ then $\operatorname{sign}\left[\frac{\partial}{\partial N^{S}} \frac{d C S^{S j}}{d \beta}\right]=\operatorname{sign}\left[\frac{d \lambda^{S j}}{d N^{S}}\right]$ which is positive. If instead $\beta^{\mathrm{k}}$ is constrained then marginal changes in $\mathrm{N}^{\mathrm{S}}$ leave $\beta^{\mathrm{k}}$ unchanged: $d \beta^{k} / d N^{S}=0$. 